\title{
KALLMANN SYNDROME - A RARE AND TREATABLE CAUSE OF MALE INFERTILITY WITH IMAGING FINDINGS
}

Rana Pratap Singh1, Khalid Mahmood ${ }^{2}$, Anshul Garg ${ }^{3}$, Kanika Goel ${ }^{4}$, Kamlesh Gunjana $^{5}$

${ }^{1} 3^{\text {rd }}$ Year Resident, Department of Urology, IGIMS, Patna.

${ }^{2}$ Assistant Professor, Department of Urology, IGIMS, Patna.

${ }^{3} 3^{\text {rd }}$ Year Resident, Department of Urology, IGIMS, Patna.

${ }^{4}$ Consultant Radiologist, Chaudhary Scan Centre, Patna.

$52^{\text {nd }}$ Year Student, Department of Urology, IGIMS, Patna.

\section{ABSTRACT}

Kallmann syndrome is a rare genetic disorder due to abnormal migration of olfactory axons and gonadotropin releasing hormone producing neurons, characterised by hypogonadism and anosmia. We report a case of Kallmann syndrome in a 20-year-old married male with characteristic clinical, biochemical and MRI findings and his management initially with testosterone to induce virilisation and later with gonadotropins to initiate spermatogenesis. The importance of the report is that it highlights a rare case where appropriate diagnosis and management could restore masculinity and probably fertility.

\section{KEYWORDS}

Kallmann Syndrome, Infertility.

HOW TO CITE THIS ARTICLE: Singh RP, Mahmood K, Garg A, et al. Kallmann syndrome - a rare and treatable cause of male infertility with imaging findings. J. Evolution Med. Dent. Sci. 2016;5(82):6154-6156, DOI: 10.14260/Jemds/2016/1391

\section{INTRODUCTION}

Kallmann syndrome is a genetic condition where the primary symptom is a failure to attain puberty and associated with additional symptoms of hypogonadism, hyposmia or Anosmia and almost invariably infertility.1,2 The most common type is an X-linked recessive disorder that occurs in 1 in every 30,000 males at birth. ${ }^{3,4}$ Kallmann syndrome occurs when the hypothalamic neurons that are responsible for releasing gonadotropin-releasing hormone fail to migrate into the hypothalamus during embryonic development.5,6 It was described by Maestre de San Juan in 1856 and characterised as a hereditary condition by Franz Josef Kallmann in 1944.7 If diagnosed can be managed by proper hormonal therapy to aid in gonadal maturation and fertility. Many aspects such as pathogenic, phenotype and genotype in KS were described in the last fifteen years.

\section{CASE HISTORY}

We report a case of a 20-year-old male who presented to us with chief complaints of small penis and erectile dysfunction. On examination, he was found to have prepubertal external genitalia and absent secondary sexual characters with associated anosmia. A normal male karyotype was found and Magnetic Resonance Imaging (MRI) of the brain showed hypoplastic left olfactory bulb and aplastic right olfactory bulb. Treatment was started with testosterone to induce virilisation with encouraging results.

Financial or Other, Competing Interest: None.

Submission 11-08-2016, Peer Review 29-09-2016,

Acceptance 05-10-2016, Published 13-10-2016.

Corresponding Author:

Rana Pratap Singh,

Lane 1B, Shivpuram,

Vijaynagar,

Rukanpura,

Patna, Bihar

E-mail: ranapratapsingh02@gmail.com

DOI: $10.14260 /$ jemds $/ 2016 / 1391$

\section{(c) (1) $(9)$}

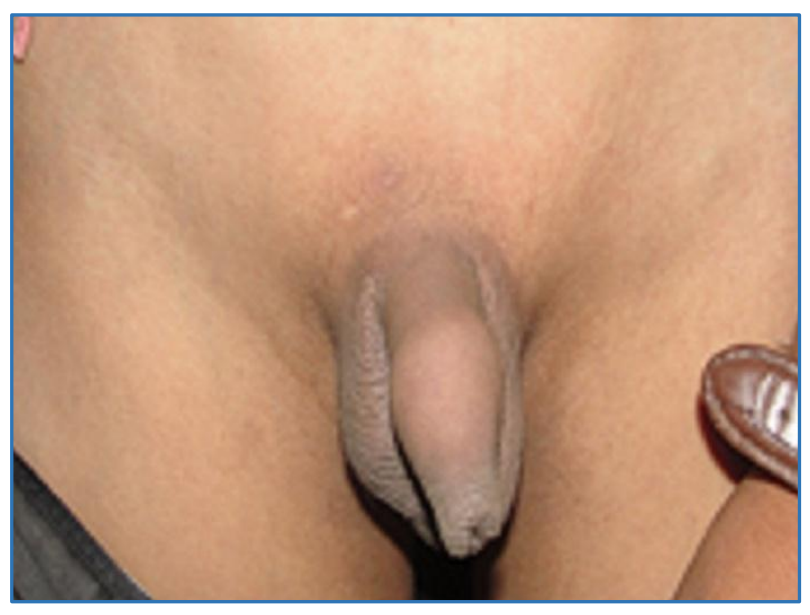

Fig. 1a: Small Penis, Prepuberal Testis, Sparse Pubic Hair

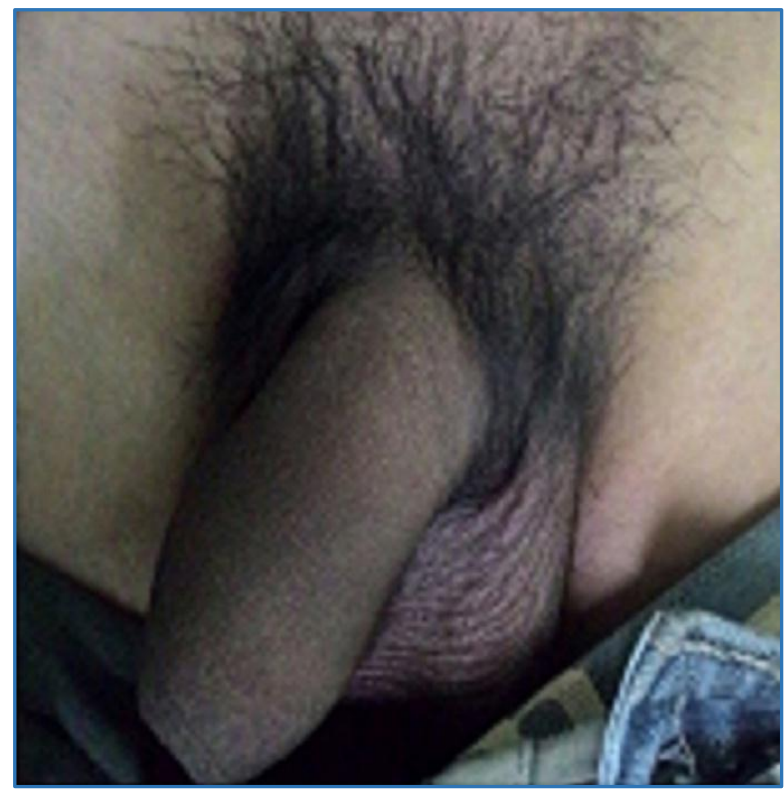

Fig. 1b: After Treatment 


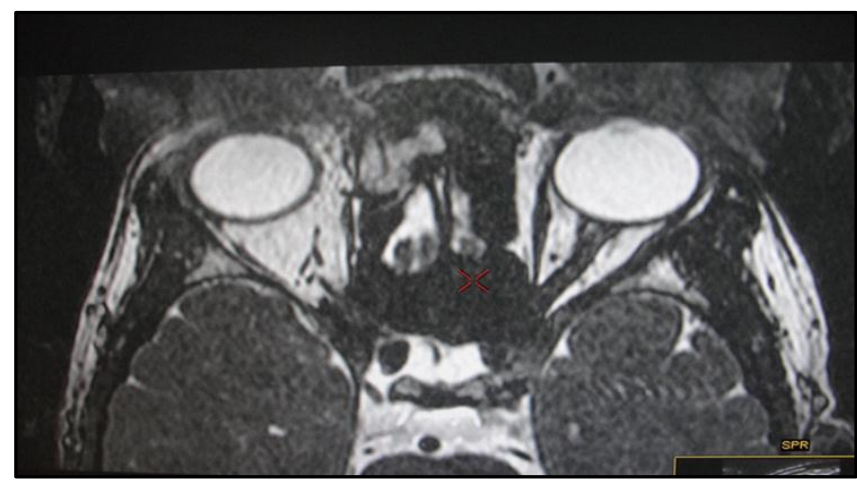

Fig. 2: MRI, Hypoplastic Left and Aplastic Right Olfactory Bulb

\section{DISCUSSION}

This twenty-year-old boy presented with failure to have intercourse following marriage eunuchoid body proportion, absence of facial and axillary hair and sparse pubic hair, high pitched voice, small sized phallus, absent libido and bilaterally descended prepubertal testes [Figure 1(a)]. The clinical picture resembled one of hypogonadism, but may have been due to delayed puberty. The presence of pubic hairs may confuse the clinician of impending fertility, but in cases of Kallmann syndrome is probably thought due to adrenal steroids.

Associated findings were anosmia since long. A hormonal assay was advised, showed primary hypogonadotropic hypogonadism with low LH, low FSH and low Testosterone. A male karyotype was found on analysis.

MRI of the brain showed hypoplastic left olfactory bulb and with effacement of furrows and aplastic right olfactory bulb [Figure 2]. MRI helps to exclude hypothalamic and pituitary lesions and differentiate from idiopathic hypogonadotropic hypogonadism, in which there is no hyposmia or MRI changes ${ }^{8}$ and clinched the diagnosis in favour of Kallmann syndrome.

The genetic locus for X-linked Kallmann syndrome has been assigned to be X p 22.3, where the KAL-1 gene encodes Anosmin 1, which plays a role in normal migration of both GnRH secreting neurons and axons of olfactory neurons from the olfactory placode to the brain, thus linking anosmia with hypogonadotropism. ${ }^{9}$ We could not have the genetic locus determined due to monetary constraints.

A thorough search for associated congenital anomalies was made, which are commonly reported with KS. ${ }^{6}$ Abdominal ultrasonography revealed no renal abnormalities and scrotal ultrasound revealed normally formed cord structures, but small size testis.

Treatment of patients with KS should be individualised. Initially, our patients' immediate goal was to have a masculine genitalia for which testosterone enanthate injections $250 \mathrm{mg}$ I.M. biweekly were given, response was seen within four months with erections, increased pubertal hair and increased penile and testicular size [Fig. 1b, c]. Androgen deficiency is treated with testosterone enanthate to effect virilisation. Therapy with testosterone usually restores virilisation in every case and patients usually begins to have ejaculation.

Human chorionic gonadotropin (hCG) treatment is initiated when fertility is desired. A careful counselling with regards to future fertility should be done as large case series have shown that sperm production is achieved only in about $50 \%$ cases, $^{10}$ if cyclic gonadotropins are initiated. The favourable parameters having a higher testicular volume at diagnosis.

Now the patient wants to have intercourse with seminal emissions for which hCG injections 1500 IU, I.M., biweekly has been started with encouraging results after twelve cycles of injections. Semen analysis after treatment shows volume $2 \mathrm{~mL}$ with severe oligozoospermia with $30 \%$ motility and $3 \%$ normal morphology. It is useful to monitor skeletal age during treatment and to discontinue treatment if there is undue skeletal advancement. Spontaneous onset of endogenous gonadotropin secretion, evidenced by progressive normalisation of testicular volume and of serum testosterone concentration has been noted in some patients over a period of years following the initial diagnosis. ${ }^{11}$

The importance of this case lies in making a correct diagnosis of a rare disease and searching for associated anomalies. Most of the clinicians think that the disease is incurable, but testosterone therapy has shown to induce virilisation in this and several other case reports in almost all cases with a variable effect on future fertility. The patients should also be told about the inheritable nature of disease if desirous of children.

\section{REFERENCES}

1. Pitteloud N, Quinton R, Pearce S, et al. Digenic mutations account for variable phenotypes in idiopathic hypogonadotropic hypogonadism. J Clin Invest 2007;117(2):457-63.

2. MacColl G, Bouloux P, Quinton R. Kallmann syndrome: adhesion, afferents, and anosmia. Neuron 2002;34(5):675-8.

3. Maya-Nunez G, Zenteno JC, Ulloa-Aguirre A, et al. A recurrent missense mutation in the KAL gene in patients with X-linked kallmann's syndrome. Journal of Clinical Endocrinology and Metabolism 1998;83(5):1650-3.

4. Sato N, Katsumata N, Kagami M, et al. Clinical assessment and mutation analysis of kallmann syndrome (KAL1) and fibroblast growth factor receptor 1 (FGFR1 or KAL2) in five families and 18 sporadic patients. J Clin Endocrinol Metab 2004;89(3):1079-88.

5. Schwanzel-Fukuda M, Bick D, Pfaff DW. Luteinizing hormone-releasing hormone (LHRH)-expressing cells do not migrate normally in an inherited hypogonadal (kallmann) syndrome. Brain Res Mol Brain Res 1989;6(4):311-26.

6. Valdes-Socin H, Rubio Almanza M, Tomé FernándezLadreda $\mathrm{M}$, et al. Reproduction, smell, and neurodevelopmental disorders: genetic defects in different hypogonadotropic hypogonadal syndromes. Front Endocrinol 2014;5:109.

7. Truwit CL, Barkovich AJ, Grumbach MM, et al. MR imaging of kallmann syndrome, a genetic disorder of neuronal migration affecting the olfactory and genital systems. AJNR Am J Neuroradiol 1993;14(4):827-38.

8. Soussi-Yanicostas N, de Castro F, Julliard AK, et al. Anosmin-1, defective in the X-linked form of kallmann syndrome, promotes axonal branch formation from olfactory bulb output neurons. Cell 2002;109(2):217-28.

9. Ribeiro RS, Vieira TC, Abucham J. Reversible kallmann syndrome: report of the first case with a KAL1 mutation and literature review. Eur J Endocrinol 2007;156(3):285290. 
10. Miyagawa $Y$, Tsujimura A, Matsumiya $K$, et al. Outcome of gonadotropin therapy for male hypogonadotropic hypogonadism at university affiliated male infertility centers: a 30-year retrospective study. J Urol 2005;173(6):2072-5.
11. Quinton R, Cheow HK, Tymms DJ. Kallmann's syndrome: is it always for life? Clin Endocrinol (Oxf) 1999;50(4):481-5. 